\title{
Rarity of Gene Transfer Between Animal and Human Isolates of Staphylococcus aureus in Vitro
}

\author{
By R. W. LACEY \\ Department of Pathology, King's Lynn General Hospital, \\ London Road, King's Lynn, Norfolk PE30 5QD
}

(Received 27 July 1979; revised 14 November 1979)

\begin{abstract}
Antibiotic-resistant Staphylococcus aureus strains of animal origin were studied for transfer of resistance to human strains in vitro, with special reference to tylosin, an antibiotic which is used only in animals. Resistance to tylosin in animal and human strains was part of a constitutive resistance to all macrolide antibiotics. Resistance to tylosin could not be transferred from animal to human strains in vitro. Transfer of other resistances occurred between few strains and at low frequency. Resistance determinants from only seven animal cultures (out of 196 tested) could donate resistance to human strains in mixed cultures. The pattern of metal ion resistance was markedly different in animal and human strains: this supports the conclusion that spontaneous transfer between them is rare in nature.
\end{abstract}

\section{INTRODUCTION}

Some antibiotics are used therapeutically in both man and animals, and may also be added at low concentrations to animal feeds to promote growth. During the last 15 years, fears have frequently been expressed that the lavish use of antibiotics in animals might prejudice their efficacy against serious infections in man (e.g. Report, 1969).

Since plasmid-coded antibiotic resistance can pass spontaneously between cultures of Staphylococcus aureus in vitro, and there is epidemiological evidence for the occurrence of this process in vivo amongst cultures pathogenic for man (Lacey, 1975), transfer of such genes might occur between strains of $S$. aureus of animal and human origin. This paper describes experiments that investigate this possibility, with particular reference to tylosin, an antibacterial agent used exclusively in animals.

\section{METHODS}

Staphylococcal strains. Five hundred isolates of Staphylococcus aureus of human origin were isolated during 1977 from clinical material in Wisbech and King's Lynn. Each was considered to be epidemiologically distinct. In addition, two cultures $(609,13136)$ of human origin known to donate resistance genes to recipients and two 'good' recipient cultures of human origin $(6936,1030)$ were used (Lacey \& Grinsted, 1973).

Two hundred and sixteen cultures of Staphylococcus aureus of animal origin were examined. Of these, 142 were from poultry, 47 from cattle, 16 from pigs, 3 from dogs, 2 from sheep and 6 from miscellaneous sources.

Cultures were identified as Staphylococcus aureus by the methods of Devriese \& Oeding (1976). Thricepurified clones were stored at room temperature on agar slopes without subculture.

Resistance determinants. Plasmids which determine resistance to neomycin (neo-r), resistance to tetracycline (tet-r), resistance to cadmium, mercury and arsenate ions and production of penicillinase (pen-r) and elements determining resistance to cadmium ions, penicillin, neomycin and streptomycin (cpns) (Lacey, 1979) or erythromycin resistance (ero-r) (Lacey \& Stokes, 1979) were obtained from human staphylococci.

Resistance transfer. This was done by the method of Lacey (1980). Resistant recipients were selected on 
Table 1. Resistance of 500 human and 216 animal strains of $S$. aureus

\begin{tabular}{lcccc}
\multicolumn{1}{c}{$\begin{array}{c}\text { Animal strains } \\
\text { Resistance }\end{array}$} & $\begin{array}{c}\text { No. } \\
\text { showing resistance }\end{array}$ & $\begin{array}{c}\text { Human strains } \\
\text { showing resistance }\end{array}$ \\
Penicillin* & 104 & 48 & 383 & $\%$ \\
Streptomycin & 27 & 13 & 41 & 87 \\
Macrolides & 13 & 6 & 72 & 14 \\
Tetracycline & 28 & 13 & 125 & 25 \\
Cadmium ions & 79 & 37 & 343 & 69 \\
Arsenate ions & 143 & 66 & 296 & 59 \\
Mercury ions & 1 & 0.5 & 236 & 47 \\
& $*$ Produce penicillinase.
\end{tabular}

medium containing $\left(\mathrm{ml}^{-1}\right)$ either $10 \mu \mathrm{g}$ fusidic acid, $50 \mu \mathrm{g}$ rifampicin or $2.5 \mu \mathrm{g}$ novobiocin with $10^{-4} \mathrm{M}-$ cadmium chloride, $50 \mu \mathrm{g}$ sodium arsenate, $5 \mu \mathrm{g}$ tetracycline, $10 \mu \mathrm{g}$ tylosin, $10 \mu \mathrm{g}$ erythromycin or $10 \mu \mathrm{g}$ streptomycin.

Bacteriophage typing. Typing was performed at routine test dilution (RTD) and included phages 94,95 and 96. A proportion of resistant recipients obtained after transfer experiments were checked for typing reactions.

Mitomycin $C$ and ultraviolet induction, and transduction experiments. These were performed as previously (Lacey, 1980).

Antibiotic sensitivity. This was determined by disc testing and the determination of minimum inhibitory concentrations (m.i.c.). For m.i.c. tests an inoculum of about 50 colony-forming units was applied with a multi-point inoculator to Mast blood agar base containing antibacterial agents. The end-point was defined as no growth after $24 \mathrm{~h}$ incubation at $37^{\circ} \mathrm{C}$. To test for inducibility, cultures were incubated overnight with antibiotic at about half the concentration required to inhibit the growth of a fully sensitive culture. Resistance to cadmium ions was defined as growth of isolated colonies on agar containing $10^{-4} \mathrm{M}$-cadmium chloride, to arsenate ions as growth on agar containing $1.0 \mathrm{mg}$ sodium arsenate $\mathrm{ml}^{-1}$, and to mercury ions as growth on agar containing $50 \mu \mathrm{g}$ mercurous chloride $\mathrm{ml}^{-1}$. Penicillinase was assayed by the method of Rosdahl (1973).

Transformation. This was attempted by the method of Lindberg \& Novick (1973).

\section{RESULTS}

\section{Antibiotic and metal ion resistance of animal staphylococci}

Of the 216 strains studied, all were sensitive to gentamicin (m.i.c. $<0.5 \mu \mathrm{g} \mathrm{ml}^{-1}$ ), neomycin (m.i.c. $<1.0 \mu \mathrm{g} \mathrm{ml}^{-1}$ ) and fusidic acid (m.i.c. $<0.5 \mu \mathrm{g} \mathrm{ml}^{-1}$ ). Resistance to tetracycline (m.i.c. $>2.5 \mu \mathrm{g} \mathrm{ml}^{-1}$ ) occurred in 28 strains $(13 \%$ ) and to streptomycin (m.i.c. $>25 \mu \mathrm{g}$ $\mathrm{ml}^{-1}$ ) in 27 strains $(13 \%$ ) (Table 1). Inducible resistance to erythromycin (m.i.c. $>1000 \mu \mathrm{g}$ $\mathrm{ml}^{-1}$ when fully induced) was seen in one culture; this was sensitive to lincomycin, tylosin and spiramycin. The distribution of m.i.c. to tylosin was bimodal. Some 204 cultures were sensitive to tylosin (m.i.c. $<2 \cdot 0 \mu \mathrm{g} \mathrm{ml}^{-1}$ ), and 12 showed high-level constitutive resistance to tylosin (m.i.c. $>1600 \mu \mathrm{g} \mathrm{ml}^{-1}$ ), erythromycin (m.i.c. $>800 \mu \mathrm{g} \mathrm{ml}^{-1}$ ), lincomycin (m.i.c. $>800 \mu \mathrm{g} \mathrm{ml}^{-1}$ ), and spiramycin (m.i.c. $>800 \mu \mathrm{g} \mathrm{ml}^{-1}$ ). All were sensitive to spectinomycin (m.i.c. $<25 \mu \mathrm{g} \mathrm{ml}^{-1}$ ). Of the tylosin-resistant cultures, five were obtained from pigs, four from poultry and three from cattle.

Penicillinase production occurred in 104 strains (48\%). Semi-quantitative assay of each penicillinase-producing culture with the chromogenic cephalosporin showed that 97 of these cultures produced low levels of enzyme and 7 produced high levels. Penicillinase from 15 of the low-level producers and from all 7 high-level producers was estimated quantitatively. The penicillinase in all these cultures was inducible following pre-incubation with $0.5 \mu \mathrm{g}$ methicillin $\mathrm{ml}^{-1}$. The high-level producers released, after induction, between 22 and 96 units 
Table 2. Transfer of macrolide resistance from human strains of S. aureus to human and animal strains

$\begin{array}{clcccc}\begin{array}{c}\text { Human } \\ \text { donor } \\ \text { strain }\end{array} & \text { Phenotype* } & \begin{array}{c}\text { Transducing } \\ \text { phage }\end{array} & \begin{array}{c}\text { Transduction } \\ \text { frequency } \\ \text { (recipient 6936) }\end{array} & \begin{array}{c}\text { From 6936 to human } \\ \text { recipient } 6936\end{array} & \begin{array}{c}\text { From } 6936 \text { to } 10 \\ \text { animal recipients }\end{array} \\ 57 & \text { ero(i), spe-r } & 85 & 7 \cdot 8 \times 10^{-5} & 3 \cdot 9 \times 10^{-7} & 7 \cdot 0 \times 10^{-9}(6) \\ 73 & \text { ero(i), spe-r } & 85 & 3 \cdot 3 \times 10^{-6} & 6 \cdot 2 \times 10^{-6} & 1 \cdot 4 \times 10^{-8}(2) \\ 109 & \text { ero(i), spe-s } & 80 & 4 \cdot 4 \times 10^{-6} & 4 \cdot 3 \times 10^{-5} & 0 \ddagger \\ 111 & \text { ero(i), spe-s } & 85 & 3 \cdot 1 \times 10^{-6} & 8 \cdot 7 \times 10^{-6} & 3 \cdot 4 \times 10^{-8}(5) \\ 133 & \text { ero(c), spe-s } & 85 & 6 \cdot 0 \times 10^{-5} & 7 \cdot 9 \times 10^{-8} & 4 \cdot 1 \times 10^{-9}(4) \\ 136 & \text { ero(c), spe-r } & 85 & 1 \cdot 8 \times 10^{-6} & 7 \cdot 3 \times 10^{-6} & 0 \\ \text { M2 } & \text { ero(c), spe-r } & 80 & 1 \cdot 0 \times 10^{-7} & <10^{-10} & 0 \\ \text { G18 } & \text { ero(c), spe-r } & 83 \mathrm{~A} & 5 \cdot 7 \times 10^{-6} & 9 \cdot 5 \times 10^{-6} & 0\end{array}$

* ero(i), inducible resistance to erythromycin and spiramicin; ero(c), constitutive resistance to all macrolide antibiotics and lincomycin; spe-s, sensitivity to spectinomycin; spe-r, resistance to spectinomycin.

$\dagger$ Mean frequency, with no. successful in parentheses.

$\ddagger$ Transfer frequency to all 10 recipients $<10^{-10}$.

per mg dry weight bacteria and the low-level producers between 2.7 and 11 units per mg dry weight. Thus, the amount of penicillinase synthesized by animal cultures is characteristically low.

Resistance to cadmium ions occurred in 79 strains $(37 \%)$ and to arsenate ions in 143 strains $(66 \%)$ but only one strain was resistant to mercury ions. There was no close association between resistance to cadmium or arsenate ions, either with each other, or with penicillinase production. In contrast, the 500 human strains examined were commonly resistant to mercury ions $(47 \%)$ and they were more often resistant to cadmium ions $(69 \%)$ than arsenate $(59 \%)$. This is in agreement with other surveys of metal ion resistance in human strains of $S$. aureus (see Dyke et al., 1970).

Approximately one-third of the animal isolates were lysed by phages of the international typing set used for human pathogens: at RTD, 44 gave major reactions to at least one phage and 34 gave minor reactions. These reactions were for a limited range of phages but included all the major phage groups.

\section{Properties of macrolide-resistant staphylococci of human origin}

Amongst the 500 recently isolated human cultures of $S$. aureus, 72 were resistant to macrolide antibiotics. Of these, 4 were sensitive and 68 were resistant to spectinomycin (m.i.c. $>200 \mu \mathrm{g} \mathrm{ml}^{-1}$ ), 65 had inducible resistance to erythromycin and spiramycin and 7 were constitutively resistant to all macrolides tested including tylosin, erythromycin, spiramycin and lincomycin. Only two of these human cultures had the full range of properties exhibited by tylosin-resistant animal staphylococci, i.e. sensitivity to spectinomycin and constitutive resistance to erythromycin, lincomycin, spiramycin and tylosin.

\section{Transfer of macrolide resistance from human staphylococci to human and animal strains}

Using propagation of typing phages $80,83 \mathrm{~A}$ or 85 the macrolide resistance from 8 human strains was transduced into human recipient 6936 . The resistant recipients always possessed the traits of the donor. Subsequently, macrolide resistance was easily transferred from 6936 to other clones of 6936 and also attempted to 10 animal strains by mixed culture incubation (Table 2). Thus, macrolide resistance could be transferred readily between human strains in vitro. Furthermore, macrolide resistance was transferred from 6936 to some animal recipients (Table 2), including the set of traits characteristic of animal cultures (sensitivity to spectinomycin and constitutive resistance to all the macrolides). 
Table 3. Transfer of resistance genes from animal strains of $S$. aureus to two human strains

\begin{tabular}{|c|c|c|c|}
\hline Animal donor strain marker(s) & $\begin{array}{l}\text { No. of } \\
\text { strains }\end{array}$ & $\begin{array}{l}\text { Human } \\
\text { recipient } \\
\text { strain }\end{array}$ & $\begin{array}{l}\text { Mean transfer } \\
\text { frequency* }\end{array}$ \\
\hline Resistance to cadmium ions & 3 & $\begin{array}{l}6936 \\
1030\end{array}$ & $\begin{array}{l}5 \times 10^{-8} \\
5 \times 10^{-9}\end{array}$ \\
\hline Resistance to cadmium and arsenate ions & 3 & $\begin{array}{l}6936 \\
1030\end{array}$ & $\begin{array}{l}2 \times 10^{-8} \\
3 \times 10^{-9}\end{array}$ \\
\hline $\begin{array}{l}\text { Resistance to cadmium and arsenate ions and penicillinase } \\
\text { production }\end{array}$ & 1 & $\begin{array}{l}6936 \\
1030\end{array}$ & $\begin{array}{l}8.0 \times 10^{-8} \\
2.0 \times 10^{-9}\end{array}$ \\
\hline
\end{tabular}

Transfer of resistance genes from animal staphylococci to human strains

Each of the animal strains resistant to cadmium ions (79), to tetracycline (28), to streptomycin (27), those constitutively resistant to macrolide antibiotics (12), and 50 strains resistant to arsenate ions were incubated separately (with appropriate controls) with each of the human recipients 6936 and 1030 . About $10^{10}$ cocci of each recipient were examined for gain of resistance in each experiment. From all these possible matings, only seven animal cultures were found that could donate resistance (Table 3). Each of these seven donors had been isolated from cattle and transferred resistance to cadmium ions to recipient 6936 at low frequency (about $10^{-8}$ ). Production of penicillinase was co-transferred in one case and resistance to arsenate ions in four. The phage type of 6936 remained unchanged after acquiring the new genes.

Each of the derivatives of 6936 that had freshly acquired cadmium ion resistance was examined for the ability to transfer this resistance to derivatives of human strains 609 , 13136, 1030 and 6936. Transfer occurred at frequencies of between $10^{-6}$ and $10^{-9}$.

Attempts to transfer cadmium ion resistance from each of the newly resistant derivatives of 6936 to 32 animal strains produced variable results. Six strains (two bovine, four poultry) acquired resistance at frequencies of $10^{-5}$ to $10^{-7}$, seven (six bovine, one poultry) acquired resistance at a lower frequency $\left(10^{-7}\right.$ to $\left.10^{-9}\right)$ and in 19 cases there was no detectable transfer $\left(<10^{-10}\right)$.

Thus resistance to cadmium ions could only be transferred from seven animal strains ( $9 \%$ of those resistant to cadmium ions) to human recipients, and this occurred at low frequency. However, once resistance to cadmium ions had appeared in human strains it was somewhat more readily transferable to other human strains. The resistance to other antibiotics (tetracycline, streptomycin, macrolides) in animal strains was not transferable to human cultures.

Attempts were made to transfer macrolide resistance from animal staphylococci to the two human recipients using lysates prepared by exposure to ultraviolet light or mitomycin $\mathrm{C}$ but these were unsuccessful. Finally, transfer by transformation was unsuccessful.

\section{Transfer of resistance genes from human staphylococci to animal strains by mixed culture}

Initially, two human donor strains, 609 and 6936, each containing one of five plasmids (tet-r, pen-r, neo-r, ero-r, cpns), were mixed with either rifampicin- or fusidic acid-resistant derivatives of 30 animal cultures. These included the seven bovine cultures able to donate their resistance to human cultures. No transfer $\left(<10^{-10}\right)$ occurred from either donor containing neo-r or ero-r, and only five animal cultures acquired tetracycline resistance from either donor, and this occurred at low frequency (Table 4). However, pen-r and cpns were 
Table 4. Transfer of resistance genes from human strains of S. aureus to 30 animal strains

\begin{tabular}{|c|c|c|c|}
\hline \multirow{2}{*}{$\begin{array}{l}\text { Human donor } \\
\text { strain (plasmid) }\end{array}$} & \multicolumn{2}{|c|}{$\begin{array}{l}\text { Animal recipients } \\
\text { acquiring resistance }\end{array}$} & \multirow{2}{*}{$\begin{array}{l}\text { Frequency of transfer* } \\
\text { (range) }\end{array}$} \\
\hline & No. & $\%$ & \\
\hline $609(t e t-r)$ & 5 & 17 & $1 \cdot 1 \times 10^{-7}-5 \cdot 5 \times 10^{-9}$ \\
\hline $6936(t e t-r)$ & 5 & 17 & $7 \cdot 0 \times 10^{-7}-6 \cdot 2 \times 10^{-9}$ \\
\hline $609($ ero-r $)$ & 0 & 0 & $<10^{-10}$ \\
\hline 6936(ero-r) & 0 & 0 & $<10^{-10}$ \\
\hline $609($ neo-r $r)$ & 0 & 0 & $<10^{-10}$ \\
\hline $6936($ neo-r $)$ & 0 & 0 & $<10^{-10}$ \\
\hline $609($ pen-r $)$ & 11 & 37 & $4.8 \times 10^{-7}-2.0 \times 10^{-9}$ \\
\hline $6936($ pen-r $)$ & 9 & 30 & $7.0 \times 10^{-7}-6.9 \times 10^{-8}$ \\
\hline $609($ cpns $)$ & 11 & 37 & $3.8 \times 10^{-7}-2 \cdot 2 \times 10^{-8}$ \\
\hline 6936(cpns) & 10 & 33 & $7 \cdot 3 \times 10^{-7}-8.8 \times 10^{-9}$ \\
\hline
\end{tabular}

* No. of resistant recipients/total no. of recipients at $24 \mathrm{~h}$. Frequency of spontaneous mutation $<10^{-10}$.

transferred to about one-third of the recipients studied at rather low frequency (approximately $10^{-7}$, Table 4).

Ten cultures that had acquired either pen-r or cpns were investigated for their ability to transfer their resistance to 20 other animal staphylococci. No further transfer was seen from five cultures, but the other five (each of which had been able to transfer resistance from animal to human cultures) could transfer their resistance to other animal staphylococci, although at low frequency (about $10^{-8}$ ).

\section{Mechanism of transfer of resistance from animal to human staphylococci}

The seven animal cultures (designated DON +) that could transfer resistance to cadmium ions to human recipients together with seven that could not (DON-) were examined further. Optimal frequency of transfer of resistance from DON + to recipients required at least $0.001 \mathrm{M}$-calcium ions, and transfer was abolished by $0.02 \mathrm{M}$-sodium citrate. Five of the $\mathrm{DON}+$ cultures but none of the DON - cultures were visibly inducible by treatment with either mitomycin $\mathrm{C}$ or ultraviolet light. Filtrates of these lysates produced plaques on several indicator strains, including culture 1030 . Two of the DON + cultures were non-typable by the 'human' set of typing phages; the remaining strains typed at RTD as $6 / 42 \mathrm{E} / 47 / 54 / 77$ / $84 / 85,29 / 52,29 / 52 / 80 / 42 \mathrm{E} / 84,29 / 52 / 80 / 42 \mathrm{E} / 54 / 84,77 / 84$. These observations are consistent with a transfer mechanism by either spontaneous phage-mediated transduction or by 'phage-mediated conjugation' (Lacey, 1980).

\section{DISCUSSION}

The chief finding from these experiments attempting transfer of genes between animal and human staphylococci is that transfer in vitro in either direction occurs at a low frequency and then only into a narrow range of recipients. Whilst a single transfer event in the presence of an antibiotic might have important clinical implications, these results do suggest that there is unlikely to be a common reservoir of resistance determinants for both animal and human staphylococci.

A number of cellular properties have been identified that have the potential to reduce the incidence of transfer of resistance by transduction or by phage-mediated conjugation; these include the failure of adsorption of phages to the recipient (Oeding, 1974; Lacey, 1980), the ability of a minority of phages to effect transduction at variable frequencies (Asheshov \& Porthouse, 1975), the presence of restriction endonucleases within the cell (Stobberingh 
\& Winkler, 1975), the requirement for the genome to become incorporated into the bacteriophage in the donor during transduction, so that large elements may be transduced only with difficulty (Chopra et al., 1973), and the presence of bacteriophage in either the donor or the recipient (Lacey, 1980).

The pattern of resistance to heavy metal ions in the animal strains differed markedly from that in the human strains. In the former, resistance to arsenate is commoner than to cadmium ions, whilst resistance to mercury ions is exceptionally rare. It is interesting that arsenate resistance in animal Enterobacteriaceae is also common (Smith, 1978).

Macrolide resistance in human strains was also different from that in animals. However, two human cultures from 72 examined were sensitive to spectinomycin and possessed constitutive resistance to all macrolides; these are characteristics of animal strains and the resistance could possibly have been transferred to them in vivo. There was no evidence that macrolide resistance in animal strains had been transferred to human strains in vivo.

I am extremely grateful for the provision of animal cultures from Drs P. Gibbs, L. A. Devriese, R. Ryden and T. Foster.

\section{REFERENCES}

Asheshov, E. H. \& Porthouse, A. (1975). The transducing abilities of different typing phages of Staphylococcus aureus. In Staphylococci and Staphylococcal Diseases, Proceedings of IIIrd International Symposium on Staphylococci and Staphylococcal Infections, pp. 307-312. Edited by J. Jeljaszewicz. Stuttgart: Gustav Fischer Verlag.

Chopra, I., BennetT, P. \& Lacey, R. W. (1973). A variety of staphylococcal plasmids present as multiple copies. Journal of General Microbiology 79, 343-345.

Devriese, L. A. \& Oeding, P. (1976). Characteristics of Staphylococcus aureus strains isolated from different animal species. Research in Veterinary Science 21, 284-291.

Dyke, K. G. H., PARKeR, M. T. \& Richmond, M. H. (1970). Penicillinase production and metal ion resistance in Staphylococcus aureus isolated from hospital patients. Journal of Medical Microbiology 3, 125-136.

LACEY, R. W. (1975). Antibiotic resistance plasmids of Staphylococcus aureus and their clinical importance. Bacteriological Reviews 39, 1-32.

LACEY, R. W. (1979). Properties of an unusual element in Staphylococcus aureus. Journal of Medical Microbiology 12, 311-320.

LACEY, R. W. (1980). Evidence for two mechanisms of plasmid transfer in mixed cultures of Staphylococcus aureus. Journal of General Microbiology 119, 423-435.

LACEY, R. W. \& GRinsted, J. (1973). Genetic analysis of methicillin-resistant strains of Staphylo- coccus aureus; evidence for their evolution from a single clone. Journal of Medical Microbiology 6, 511-526.

LaceY, R. W. \& Stokes, A. (1979). Studies on recently isolated cultures of methicillin-resistant Staphylococcus aureus. Journal of General Microbiology 114, 329-339.

Lindberg, M. \& Novick, R. P. (1973). Plasmidspecific transformation in Staphylococcus aureus. Journal of Bacteriology 115, 139-145.

OEdING, P. (1974). Cellular antigens of staphylococci. Annals of New York Academy of Sciences 236, 15-21.

REPORT (1969). Joint Committee on the Use of Antibiotics in Animal Husbandry and Veterinary Medicine. London: Her Majesty's Stationery Office.

RosDAHL, V. T. (1973). Naturally occurring constitutive $\beta$-lactamase of novel serotype in Staphylococcus aureus. Journal of General Microbiology 77, 229-231.

Smith, H. Williams (1978). Arsenic resistance in enterobacteria; its transmission by conjugation and by phage. Journal of General Microbiology 109, 49-56.

Stobberingh, E. E. \& WinkLer, K. C. (1975). Restrictionless mutants of Staphylococcus aureus. In Staphylococci and Staphylococcal Diseases, Proceedings of IIIrd International Symposium on Staphylococci and Staphylococcal Infections, pp. 313-324. Edited by J. Jeljaszewicz. Stuttgart: Gustav Fischer Verlag. 